\title{
Determinant Factors of Work-Related Complaints
}

\author{
Qoni Mulia Sagita ${ }^{1}$, Yuliani Setyaningsih ${ }^{2}$, Sulistiyani $^{3}$
}

Public Health Faculty, Universitas Diponegoro, Semarang, Indonesia

\begin{tabular}{l} 
Article Info \\
\hline Article history: \\
Received Nov 9, 2017 \\
Revised Mar 12, 2018 \\
Accepted Mar 26, 2018 \\
\hline
\end{tabular}

\section{Keyword:}

Workers of shoe industry

Medical history

Respondent characteristic

Personal protective equipment

Work-related complaints

\begin{abstract}
Home-based workers of Footwear industries in Semarang Regency are all womans. The employment status of home-based workers usually unrecognized or unregulated by the employer or their itermediaries so that they did not paid close attention about HWBs's working condition. They often work on inadequate working environment such as poor ventilation system, bad lighting, humid working space (damp wall and floor), and also poor layout of furnitures and work equipments. That condition exaberated by lack of HWBs's knowledge and awareness regarding their health and safety at work. In addition HBWs often with little to none education, work on long extended working hours and working under intensive labor.This research was aimed to determine the relationship between respondent characteristics, medical history, and use of PPE with work-related complaints on home workers of shoe industry in Semarang regency. This was an observational analytic study using cross sectional approach. Population in this study was 80 home workers of shoe industry in Semarang regency. The samples are 66 home workers were taken using stratified random sampling method. Data were analyzed using frequency distribution and Chi-Square test. The results of this study showed that there were some variables that have significant association with work-related complaints $(\mathrm{p} \leq 0.05)$ including, length of work, duration of work, personal protective equipment (PPE). While the variables of age, body mass index (BMI), and medical history did not show significant association with work-related complaints ( $p>0.05$ ). Multivariate analysis using logistic regression showed the duration of work had the most powerful influence to the work-related complaints. The conclusion of this study was important for home workers to maintain health condition by doing exercise to avoid work-related complaints. Home workers that have long duration of work should increase the use of PPE such as masks and gloves.
\end{abstract}

Copyright $@ 2018$ Institute of Advanced Engineering and Science. All rights reserved.

\section{Corresponding Author:}

Qoni Mulia Sagita,

Public Health Faculty,

Universitas Diponegoro,

J1 Prof Soedarto SH Tembalang, Semarang-50275, Indonesia.

Email: qonimuliasagita@gmail.com

\section{INTRODUCTION}

In every countries, both developed and developing countries wide range production of low and highend goods and services for domestic and global market are increasing. This triggers the flourish of self employed workers and/or working at home workers. Home based workers is one of the work at home types [1]. Home-based workers (HBWs) are workers who are self-employed (independent) or subcontracted workers who work directly or indirectly for employer or their intermediaries on a piece rate basis payment and usually most of them are women [2]. Home based work does not require high skills technique, does not leave home and daily tasks and make money quickly so it is suitable to be done by women [3]. Home-based workers produce goods or service for the market from within or around their own homes [4]. 
Researches describes various impact of self-employed work and/or working at home on health and safety of the HBWs. Particular health hazard will have spesific problem on health. From a survey on women in South Australia, 70\% of HBWs experienced problem because of their works, raging from exposure of toxic substance, occupational injuries related to long working hour, stress and high level of fatique [5].

Home-based workers of Footwear industries in Semarang Regency are all womans. The employment status of HBWs usually unrecognized or unregulated by the employer or their itermediaries so that they did not paid close attention about HWBs's working condition. They often work on inadequate working environment such as poor ventilation system, bad lighting, humid working space (damp wall and floor), and also poor layout of furnitures and work equipments. That condition exaberated by lack of HWBs's knowledge and awareness regarding their health and safety at work. In addition HBWs often with little to none education, work on long extended working hours and working under intensive labor.

The principle of occupational health is an effort to harmonize between work capacity, workload and work environment so that every worker can work healthily to obtain optimal work productivity [6]. This research was aimed to analyse the influence of respondent characteristics, medical histories, and the use of PPE to work-related complaints of home-based workers of footwear industries.

\section{RESEARCH METHOD}

\subsection{Subject and Materials}

This was an observational research with cross sectional design. The study was conducted on homebased workers of footwear industry in Semarang Regency. Population in this study was all 80 home-based workers of footwear industries in Semarang Regency. The samples were taken using stratified random sampling method. In this research population divided into 3 sub-populations that are formed based on subdistrict (Bawen, Bergas and Pringapus). Minimum samples calculated using lameshow formula and sampled

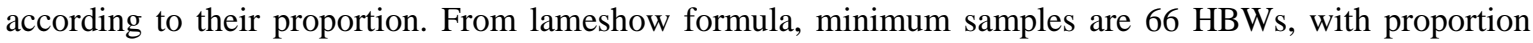
$37.5 \%$ from Bawen sun-distric (25 HBWs), 37.5\% from Bergas sub-district (25 HBWs) and 25\% from Pringapus sub-ditrict (16 HBWs). The inclusion criteria was workers who willing to be respondent of this research and work as HBW at footwear industries in Semarang Regency.

Work-related complaints in this study were categorized into two groups, complex and simple.HBWs work-related complaints consist of breathless, headache, eye irritation, upper back pain, lower back pain, stiff shoulder, tremors, menstrual disorders, nauseous vomit, itchy and callus. This data were collected using questionnaires through interview.

\subsection{Statistical Analysis}

Chi square test was used to analyse bivariate data including age, length of work, duration of work, body mass index, medical histories, and use of personal protective equipment. Logistic regression was used to analyse the factors affected the work-related complaints.

\section{RESULTS AND ANALYSIS}

\subsection{Bivariate Analysis}

Respondent' ages in this study varies from 23 to 66 years old. There were $84.8 \%$ of workers suffered from callus due to sewing job. As for the working period, it ranges between one to 24 years. Many of home workers worked more than 8 hours each day. Working for long period increasing risk of health problems such as musculosceletal pain that may be related toencroachment on recovery and recuperation time from working day before or opportunities to heal or recover to baseline. The relationship of overtime to injury has been reported with injury risks increasing as hours increased [7].

Table 1 shows the result of the bivariat analysis. There were $92.4 \%$ of respondent have productive age that is between 15 to 64 years old. $66.7 \%$ of the respondents have working period more than 3 years as HBWs. In addition, $75.8 \%$ of respondent had unqualified duration of work with averageworking duration more than 9 hours a day. This value was higher than a normal range for duration of work for industrial workers [8]. There were as many as 35 people $(53.0 \%)$ of respondent who have an abnormal body mass index with the value $<18.5 \mathrm{~kg} / \mathrm{m}^{2}$ or $>24.9 \mathrm{~kg} / \mathrm{m}^{2}$. However, $77.3 \%$ of the respondents have no medical historiesof degenerative disease. Respondents were more likely to not use personal protective equipment such as mask and gloves during work (77.3\%).

The bivariate analysis showed that there were some variables that have significant association with work-related complaints $(\mathrm{p} \leq 0.05)$ including, length of work, duration of work, and use of personal protective equipment (PPE). While the variables of age, body mass index (BMI), and medical histories did not show significant association with work-related complaints $(\mathrm{p}>0.05)$. This result showed that work-related 
complaint might happen to HBWs in every age range, to every fat or thin people and peoples with or without history of degenerative disease. Respondents whose suffered from work-related complaints may caused by work under long working hours and long periode time (more than 3 years) and lack of PPE usage. From research on working adults in USA show that long working hours indirectly precipitate workplace accidents by inducing fatigue or stress in affected workers and overtime schedules had the greatest relative risk of occupational injury or illness, followed by schedules with extended $(>12)$ hours per day and extended $(>60)$ hours per week [9]. in other studies Workers remain unaware of and are not interested in occupational hazards despite training in hazards at work [10].

Table 1. Bivariate Analysis between Age, Length of Work, Duration of Work, Body Mass Index, Medical History, and Use of Personal Protective Equipment with Work-related Complaints.

\begin{tabular}{lcccc}
\hline \multicolumn{1}{c}{ Variabels } & $\mathrm{N}(\%)$ & $P$ & $\mathrm{PR}$ & $95 \% \mathrm{CI}$ \\
\hline Age & & 0.194 & 0.330 & $0.754-3.382$ \\
$\quad$ Unproductive & $5(7.6)$ & & & \\
$\quad$ Productive & $61(92.4)$ & & & \\
Length of work & & 0.001 & 3.300 & $1.499-7.265$ \\
$\quad$ Long & $44(66.7)$ & & & \\
$\quad$ Short & $22(33.3)$ & & & \\
Duration of work & & 0.001 & 11.840 & $1.762-79.544$ \\
$\quad$ Unqualified & $50(75.8)$ & & & \\
$\quad$ Qualified & $16(24.2)$ & & & \\
Body mass index & & 0.501 & 1.218 & $0.796-1.864$ \\
$\quad$ Abnormal & $35(53.0)$ & & & \\
$\quad$ Normal & $31(47.0)$ & & & \\
Medical History & & 1.000 & 1.055 & $0.655-1.701$ \\
$\quad$ Yes & $15(22.7)$ & & & \\
$\quad$ No & $51(77.3)$ & & & \\
Use of PPE & & 0.002 & 3.431 & $1.226-9.602$ \\
$\quad$ Incomplete & $51(77.3)$ & & & \\
$\quad$ Complete & $15(22.7)$ & & & \\
\hline
\end{tabular}

Duration of work was work stressors that vary greatly both in quality and quantity. The longer a person works on a job, the more fatigue would occur [11]. Bivariate test results showed that there were an association between duration of work with work-related complaints. The length of work in this study could affect both positive and negative performance. Positive influence on performance was occurred if home workers with increasing length of work more experienced in carrying out its duty. Conversely give negative influence if with increasing length of work would increase health trouble to worker and increase boredom caused by worker which is monotonous.

\subsection{Multivariat Analysis}

Table 2 shows that duration of work, use of Personnel Protective Equipment (PPE), and length of work were associated with work-related complaints. Duration of work had the lowest significant level compared to all other variables $(\mathrm{p}=0.002)$. The relationship between duration of work, use of PPE, and length of work can be seen from the logistics test results. Duration of work had the strongest influence toward workrelated complaints to other variables. Duration of work had adjusted OR value 40.665 , which means that home-based workers of footwear industries in Semarang Regency who had unqualified duration of work were likely to have 40.665 times the risk of work-related complaints.

Table 2. Summary of Logistic Regression Results that is Statisticaly Significant

\begin{tabular}{lcccc}
\hline \multicolumn{1}{c}{ Variabels } & B & $P$ & Adjusted OR & $95 \%$ CI \\
\hline Duration of work & 3.705 & 0.002 & 40.655 & $3.898-424.032$ \\
Use of PPE & 2.753 & 0.003 & 15.692 & $2.601-94.680$ \\
Length of work & 2.283 & 0.006 & 9.806 & $1.918-50.136$ \\
Constant & -6.228 & & & \\
\hline
\end{tabular}

The duration of work was related to the physical condition of the worker's body. Long working hours defined as work more than 40 hours per week and extended work shifts are defined as a shift longer than 8 hours per day. Few studies have explored how much long working hours influence workers with preexisting health problems, or how the hours relate to symptom management and the course of common 
chronic diseases. The present report was limited to a summary of those studies that addressed associations between long working hours and illnesses, injuries, health behaviors, and performance [8].

Home-based workers of footwear industries often had to pursue productiontime and numbers that unmatch with the terms of provisions. Workers usually had to complete up to 20 pairs of footwear within two days. Based on the results of interview, workers could finish 1 pair of footwearwithing one hour so at least the workers need to work 10 hours a day. All the workers who sewed the footwear are female. Therefore, they often had to multitask between work and household activities which certainly added to their physical and emotional burden. Long hours can lead to sleep deprivation, and that associated risks of illness and injury are exacerbated by high workloads and shift work [12].

This study was consistent with the research conducted by Spurgeon et al, which state that onset of fatigue was the result of working for long hours. It directly affected the safety behavior of the workers. Studies have shown that health effects arised with over 50 work hours a week. Numerous problems associated includes stress disorders, musculoskeletal disorders, etc., might also be associated with long working hours [13].

Footwear industries home-based workers were exposed to health hazards like every other worker. The hazards including exposure to dangerous chemicals, repetitive work, awkward posture and impaled needle.It was therefore important for home workers to be aware of the Personnel Protective Equipment (PPE) and the practice of safety precautions related to their work [14]. PPE are used differently for different purposes, clean and well keep and are not to be shared among workers. Some workers in this study claimed that they felt uncomfortable using PPE while doing their work. One of the PPE in the form of finger sheath was rarely used, so most respondents experience callus. On the study to farmer, they wore the protective devices when exposure to hazard was excessive and the use of these protective devices may less frequent when they did not perceive a high level of risk or if they had not experienced a health problem due to the exposure [15].

Many respondents complained of shortness of breath, asphyxia and skin itching when sewing leather shoes made of velvet material. This complaint often caused by respondents did not use proper PPE. In addition, the company did not provide enough PPE such as masks and gloves. The lack of employer attention in providing PPE is also one of the causes of workers not using PPE [16]. The use of PPE could play an important role in safeguarding the health and life of workers in any working environment. It is also important to realize that PPE like any other protection does not eliminate danger, but simply serves as a screen between the worker and the source of danger. In most cases the danger and injury [17]. Healthy workers are more likely to be better motivated, enjoy greater job satisfaction and contribute to better-quality products and services, thereby enhancing the overall quality of life of individuals and society [3].

\section{CONCLUSION}

Duration of work, use of PPE, and length of work can affect work-related complaints of home-based workers of footwear industries in Semarang Regency. Home-based workers need to maintainn their health condition by doing regular physical exercise to reduce work-related complaints. Home-based workers that have long duration of work should increase the use of PPE such as masks and gloves to make barrier between them and occupation hazard.

\section{REFERENCES}

[1] V. C. Ozguler, et al., "Home-Based Woman Workers: The Case of Turkey / Eskisehir," International Journal of Business and Social Science, vol/issue: 3(19), pp. 262-271, 2012.

[2] N. Haspels and A. Matsuura, "Home-based Workers : Decent work and social protection through organization and empowerment," International Labor Office, Jakarta: ILO, 2015.

[3] Pieper and Anton P. P., "Working Conditions in the Indonesian Leather and Footwear Sector," Grobe N., ed., Bonn, Sudwind e.V, 2017.

[4] M. A. Chen and S. Sinha., "Home-based Workers and Cities," International Institute for Environment and Development, vol. 28, pp. 343-358, 2016.

[5] J. Tassie, "Home Based Worker at Risk: Outworkers and occupational Health and Safety," Elsevier Science Ltd, Safety Science, vol/issue: 25(1-3), pp. 179-186, 1997.

[6] B. O. Ali, "Fundamental Principles of Occupational Health and Safety," International Labour Office, Geneva, ILO, 2008.

[7] A. M. Trinkoff, "Longitudinal Relationship of Work Hours, Mandatory Overtime, and On-call to Musculoskeletal Problems in Nurses," American Journal Of Industrial Medicine, vol. 49, pp. 964-971, 2006.

[8] Caruso, Claire C., et al., "Overtime and Extended Work Shift: Recent Findings on Illnesses, Injuries, and Health Behaviors," US Departemen of Health and Human Services, National Institute for Occupational Safety and Health, Columbia, 2004 
[9] A. E. Dembe, et al., "The impact of overtime and long work hours on occupational injuries and illnesses: new evidence from the United States," Occup Environ Med, vol. 62, pp. 588-597, 2005.

[10] M. S. Chen and C. L. Huang, "Industrial Workers' Health and Environmental Pollution under the New International Division of Labor: The Taiwan Experience," American Journal of Public Health, vol/issue: 87(7), 1997.

[11] A. S. Wagstaff and J. A. S. Lie, "Shift and Night Work and Long Working Hours- A Systematic Review of Safety Implications," Journal Scand J Work Environ Health, vol/issue: 37(3), pp. 173-185, 2011.

[12] C. C. Caruso, "Long Working Hours, Safety, and Health: Toward a National Research Agenda," American Journal Of Industrial Medicine, vol. 49, pp. 930-942, 2006.

[13] Spurgeon A., et al., "Health and Safety Problems Associated with Long Working Hours: A Review of the Current Position," Journal of Occupational and Environmental Medicine, vol/issue: 54(6), pp. 367-375, 1997.

[14] T. S. Oguntona, et al., "Awareness and Use of Personal Protective Equipment (PPE) and Practice of Safety Precautions among Funeral Home Workers in Lagos State," Transnational Journal of Science and Technology, vol/issue: 2(9), 2012.

[15] D. B. Reed, "Personal Protective Equipment Use and Safety Behaviors Among Farm Adolescents: Gender Differences and Predictors of Work Practices," National Rural Health Association, vol/issue: 22(4), 2006.

[16] T. S. Oguntona, "Awareness and Use Of Personal Protective Equipment and Practice of Safety Precaution among Funeral Home Workers in Lagos State," Transnational Journal of Science and Technology, vol/issue: 2(9), 2012.

[17] R. S. Konya, et al., "The Use of Personal Protective Equipment (PPE) among Workers of Five Refuse Disposal Companies within Port Harcourt Metropolis, Rivers State, Nigeria," Asian Journal of Applied Sciences, vol/issue: 01(05), 2013. 